\title{
BMJ Open Age distribution and types of breast lesions among Afghan women diagnosed by fine needle aspiration cytology (FNAC) at a tertiary care centre in Afghanistan: a descriptive cross- sectional study
}

\author{
Ramin Saadaat, ${ }^{1}$ Jamshid Abdul-Ghafar (D) , ${ }^{1}$ Ahmed Maseh Haidary, ${ }^{1}$ \\ Soma Rahmani, ${ }^{1}$ Nooria Atta $^{2}$
}

To cite: Saadaat $R$, AbdulGhafar J, Haidary AM, et al. Age distribution and types of breast lesions among Afghan women diagnosed by fine needle aspiration cytology (FNAC) at a tertiary care centre in Afghanistan: a descriptive crosssectional study. BMJ Open 2020;10:e037513. doi:10.1136/ bmjopen-2020-037513

- Prepublication history for this paper is available online. To view these files, please visit the journal online (http://dx.doi org/10.1136/bmjopen-2020037513).

Received 06 February 2020 Revised 22 July 2020 Accepted 27 July 2020

Check for updates

(c) Author(s) (or their employer(s)) 2020. Re-use permitted under CC BY-NC. No commercial re-use. See rights and permissions. Published by BMJ.

${ }^{1}$ Department of Pathology and Clinical Laboratory, French Medical Institute for Mothers and Children (FMIC), Kabul, Afghanistan

${ }^{2}$ Department of Gynecology and Obstetrics, Kabul University of Medical Sciences (KUMS), Kabul, Afghanistan

Correspondence to Dr Jamshid Abdul-Ghafar; jamshid.jalal@fmic.org.af

\section{ABSTRACT}

Objectives In Afghanistan, breast diseases are a common reason for women to visit hospitals. This is the first study in Afghanistan aimed to describe the age distribution and types of breast diseases among patients diagnosed by fine needle aspiration cytology.

Design Descriptive cross-sectional study.

Setting French Medical Institute for Mothers and Children, Kabul, Afghanistan.

Participants The study included 650 patients with breast lesions between 1 April 2015 and 1 April 2019.

Results The mean age of diagnosis was 35.38 (SD \pm 13.11 ) years, ranging from 15 to 75 years. The most common diagnosis was cancer ( $24 \%$ of all cases). The second most common diagnosed lesion was fibroadenoma, constituting $22.4 \%$, and the third most common lesion was fibrocystic changes, with $15.4 \%$ of cases. Inflammatory conditions were diagnosed in $9.7 \%$ of cases, granulomatous inflammation in $9.1 \%$, lesions only suspicious for malignancy in 5.5\%, lipoma in $2.8 \%$ and miscellaneous benign lesions in $11.1 \%$. Cancer was diagnosed at the youngest age of 20 years. Cancer was more common on the left side $(62 \%)$, and only one case $(0.9 \%)$ was bilateral.

Conclusion Our study showed that cancer was the most commonly diagnosed lesion and was reported at younger ages too. This suggests that physicians should not ignore any breast lump in younger patients and that the possibility of cancer must be considered. Further countrywide studies are suggested to assess breast cancer and associated risk factors.

\section{BACKGROUND}

The glandular structure of the breast can undergo changes from puberty to pregnancy and menopause due to hormonal effects. Benign lesions of the breast are common in younger age groups, while malignant lesions are common in older age groups. ${ }^{12}$ Breast lesions can be palpable at $2 \mathrm{~cm}$ or more in
Strengths and limitations of this study

- This is the first study on female breast lesions done in Afghanistan, a country with very limited standard pathology centres.

- The main focus was on the type of breast lesions and the age of involvement.

- The sample size was limited to a single centre.

- The study is retrospective, so we were not able to obtain more information from the participants.

size or can be non-palpable, and can sometimes be felt by the patient as heaviness in the affected breast. Some cases are associated with pain and nipple discharge, while others are completely asymptomatic.

Breast cancer (BC) is the most common cancer in women and the second most common in both genders after lung cancer. In 2018, there were 2088849 (11.6\% of all cancers) new cases of BC, and this resulted in 626679 (6.6\% of all cancers) deaths worldwide. ${ }^{4}$ In Afghanistan, BC is the most common cancer diagnosed in women, with 3062 total new cases diagnosed only in 2018, which accounted for $15.7 \%$ of all cancers, as reported by Global Cancer Incidence, Mortality and Prevalence (GLOBOCAN). ${ }^{5}$ These data are estimates from neighbouring countries and are not true representative cancer data in Afghanistan. Despite the fact that most breast lesions are benign, benign proliferative breast lesions with atypia have higher risk for cancer than without atypia. ${ }^{6}$ Common risk factors are reproductive factors, alcohol intake, high breast density, postmenopausal hormone replacement therapy 
and most importantly family history of BC. Family history of other cancers such as colon, ovary and prostate is also a known risk factor for BC. ${ }^{78}$

The triple test investigation, which includes clinical evaluation, radiological examination and pathological examination, reduces the likelihood of missing the diagnosis to less than $1 \% .^{3}$ Fine needle aspiration cytology (FNAC) is a reliable and useful method for early assessment of breast lesions. ${ }^{69}$ FNAC is sensitive, simple and less expensive compared with biopsy for histopathological examination, does not require patient admission, does not require general anaesthesia, can be repeated multiple times, allows multisite sampling, saves time, and is also useful in evaluating axillary nodes. FNAC is commonly used to evaluate whether the breast lump is benign or malignant, but it also allows classification of subtypes of benign and malignant lesions. ${ }^{10}$

A large part of our routine patients at French Medical Institute for Mothers and Children (FMIC) are women with breast lumps who visit the hospital for FNAC and/ or biopsy; however, no study has been carried out on the profile of breast diseases in Afghanistan. Therefore, the current study was conducted at FMIC, a tertiary care institute, to describe the profile of benign and malignant breast lesions, along with their age distribution.

\section{MATERIALS AND METHODS}

\section{Study design and setting}

This was a descriptive cross-sectional study conducted on patients diagnosed with breast lesions by FNAC at the Department of Pathology and Clinical Laboratory of FMIC. This is the only well-equipped tertiary care hospital that provides standard histopathology services in Afghanistan. The institution first started providing basic histopathology services in early 2006, was CURE International hospital assisted by missionary retired pathologists from the USA, with very basic equipment and limited cases. Majority of cases were outsourced to neighbouring countries for proper diagnosis. FMIC started providing histopathology services in 2015, when the only $\mathrm{PhD}$ holder pathologist (Dr. Jamshid Abdul-Ghafar) of the country, who had received training in South Korea, joined the institution. Accordingly, through his endeavours, by 2016, FMIC was able to commence residency training programme in histopathology under the banner Postgraduate Medical Education programme, and it was in early 2019 when the institution's first resident graduated as a histopathologist. Currently, the hospital provides cytopathology and histopathology services to all patients.

\section{Study population}

The study included all patients diagnosed by FNAC for breast lesions from 1 April 2015 to 1 April 2019 at the Department of Pathology and Clinical Laboratory of FMIC.

\section{Data gathering}

Data on patients' age, gender, type of lesion and side of lesion were retrieved from medical records of patients who underwent breast FNAC at FMIC. Aspiration from breast lumps was performed using 10-gauge needles, and the aspirated material was smeared on at least four slides. For deeply located lesions, which were not palpable, ultrasound-guided fine needle aspiration was performed at the Department of Radiology of FMIC. All smeared slides were fixed using spray fixative, except one which was air-dried and used for rapid stain (Diff-Quik stain) to confirm the cellularity of the aspirated materials. The procedure was repeated whenever the aspirate was not satisfactory. The slides were stained with H\&E and Pap stain methods. The stained slides were then examined under the microscope for diagnosis.

\section{Sample size}

A total of 650 diagnosed FNAC cases were retrieved from the medical record. Breast lesions were divided into benign and malignant, with all breast lesions further subdivided into eight categories: cancer, suspicious for malignancy, fibroadenoma, fibrocystic changes (FCC), inflammatory conditions, granulomatous inflammation and lipoma, while other breast lesions such as negative for malignancy without specific subtyping, lactating adenoma, galactocele and phyllodes tumour, which accounted for lower percentages, were labelled as miscellaneous.

The age of the patients was classified into five age groups (15-25, 26-35, 36-45, 46-55 and $>55$ years). BCs were also divided according to side of involvement, as right, left and bilateral.

\section{Statistical analysis}

All data were analysed through Statistical Package for Social Sciences (SPSS) V.25. Frequency and percentage were evaluated for categorical data. Mean and SD were evaluated for continuous data.

\section{Patient and public involvement}

No patients were involved in defining the research question or the outcome measures, and in the design and implementation of the study. There are no plans to involve patients in the dissemination of the results.

\section{RESULTS}

The common age group in our study was between 15 and 25 years $(28.6 \%)$. The most prevalent diagnosis among all the samples in this study was cancer, which constituted $24 \%$ of all diagnosed cases, while $5.5 \%$ of cases were suspected for malignancy (figure 1). Only one case was lymphoma, and the rest of the cases were diagnosed as ductal carcinomas. The mean age at cancer diagnosis was 43.6 years and the youngest age at diagnosis was 20 years, with the majority occurring in the $36-45$ years age group. The cases that were labelled to be suspected for malignancy occurred mostly in the $36-45$ years age group, with an average age of 43.4 years and with the youngest age of 17 years (tables 1 and 2). The second most common lesion was fibroadenoma, which constituted $22.4 \%$ of cases, with 


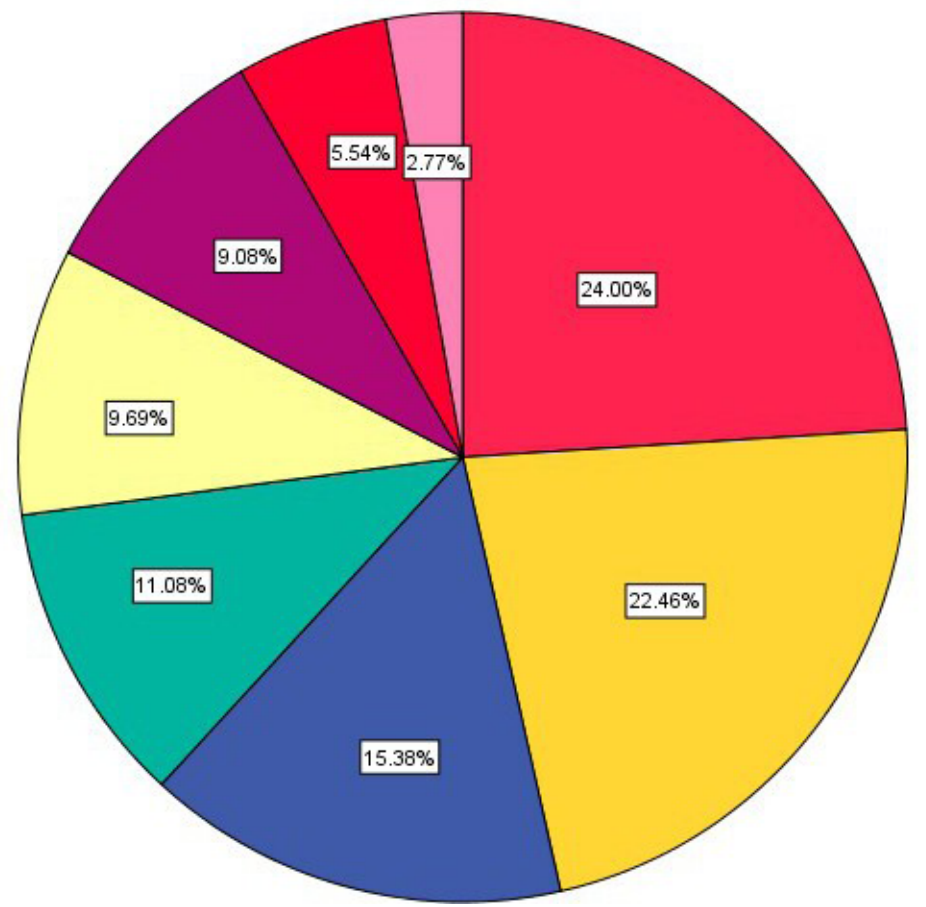

$\square$ Cancer

$\square$ Fibroadenoma

Fibrocystic changes

Miscellaneous lesions

$\square$ Inflammation

Granulomatous inflammation

Suspicious for malignancy

Lipoma

Figure 1 Distribution and pattern of benign and malignant breast lesions.

a mean age of 23.4 years and with 15 years as the youngest age of diagnosis. FCC was the third most common lesion, which constituted $15.4 \%$ of cases, with a mean age of 36.6 years. Inflammatory conditions constituted $9.7 \%$ and granulomatous inflammation $9.1 \%$ of cases, both occurring in the 26-35 years age group. Lipoma comprised $2.8 \%$ of cases. Lesions such as galactocele, benign phyllodes tumour, lactating adenoma, fat necrosis and benign but unclassifiable lesions were labelled as 'miscellaneous' and consisted of 72 cases $(11.1 \%)$. Most cancers were on the left side $(62 \%)$, with only one bilateral case $(0.9 \%)$.

Table 1 Age distribution of the breast lesions

\begin{tabular}{llll}
\hline Variables & $\begin{array}{l}\text { Frequency } \\
(\%)\end{array}$ & $\begin{array}{l}\text { Age, } \\
\text { mean } \pm \text { SD }\end{array}$ & $\begin{array}{l}\text { Age in years, } \\
\text { minimum/ } \\
\text { maximum }\end{array}$ \\
\hline $\begin{array}{l}\text { Malignant cancer } \\
\text { Fibroadenoma }\end{array}$ & $146(24)$ & $43.6 \pm 12.7$ & $20 / 75$ \\
$\begin{array}{l}\text { Fibrocystic } \\
\text { changes }\end{array}$ & $100(15.4)$ & $36.68 \pm 12.4$ & $16 / 75$ \\
$\begin{array}{l}\text { Suspicious for } \\
\text { malignancy }\end{array}$ & $36(5.5)$ & $43.47 \pm 15.3$ & $17 / 80$ \\
$\begin{array}{l}\text { Granulomatosis } \\
\text { mastitis }\end{array}$ & $59(9.1)$ & $36.02 \pm 10.2$ & $15 / 70$ \\
Inflammation & $63(9.7)$ & $32.92 \pm 8.2$ & $18 / 51$ \\
\hline $\begin{array}{l}\text { Lipoma } \\
\text { Miscellaneous }\end{array}$ & $18(2.8)$ & $42.22 \pm 9.3$ & $25 / 60$ \\
\hline $\begin{array}{l}\text { Total } \\
611.1)\end{array}$ & $34.18 \pm 11.7$ & $15 / 70$ \\
\hline
\end{tabular}

\section{DISCUSSION}

Lesions in the breast are among the reasons why women worldwide seek medical attention. Although most of the breast lesions are benign, malignant neoplasms of the breast have the highest incidence and are associated with high mortality rates among women. ${ }^{11}$ To the best of our knowledge, in Afghanistan no data have ever been published regarding the distribution of $\mathrm{BC}$ and other disorders of the breast. Since our institution has the standard facility for histopathology and cytopathology, many patients with breast lesions visit our department for FNAC procedure and diagnostic cytology. The current study covers the largest population at a tertiary healthcare level in Afghanistan.

Table 2 Age group distribution of breast lesions

\begin{tabular}{|c|c|c|c|c|c|c|}
\hline \multirow[b]{2}{*}{ Variables } & \multicolumn{5}{|c|}{ Age in years $(\%)$} & \multirow[b]{2}{*}{ Total } \\
\hline & $15-25$ & 26-35 & $36-45$ & $46-55$ & $>55$ & \\
\hline Malignant cancer & 5.8 & 23.7 & 30.8 & 23.1 & 16.7 & 100 \\
\hline Fibroadenoma & 74.4 & 17.8 & 7.5 & 0 & 0 & 100 \\
\hline $\begin{array}{l}\text { Fibrocystic } \\
\text { changes }\end{array}$ & 21 & 31 & 29 & 12 & 7 & 100 \\
\hline $\begin{array}{l}\text { Suspicious for } \\
\text { malignancy }\end{array}$ & 13.9 & 19.4 & 30.6 & 13.9 & 22.2 & 100 \\
\hline $\begin{array}{l}\text { Granulomatosis } \\
\text { mastitis }\end{array}$ & 11.9 & 47.5 & 25.4 & 11.9 & 3.4 & 100 \\
\hline Inflammation & 23.8 & 34.9 & 34.9 & 6.3 & 0 & 100 \\
\hline Lipoma & 5.6 & 22.2 & 38.9 & 27.8 & 5.6 & 100 \\
\hline Miscellaneous & 25 & 33.3 & 27.8 & 9.7 & 4.2 & 100 \\
\hline
\end{tabular}


In our study, majority of the breast lesions were benign tumours and cystic changes $(51.7 \%)$. Malignant cancer and suspected cases for malignancy accounted for $29.5 \%$ of cases, and inflammatory diseases including granulomatous inflammation made up $18.8 \%$ of all FNAC cases. These findings are similar with the findings found in studies by Kochhar et $a l^{12}$ in India and by Ghasemzadeh et $a l^{13}$ in Iran. ${ }^{12}$

The largest proportion of the lesions in our study was cancer, which was consistent with studies conducted in Pakistan, reporting $37 \%{ }^{14}$ and $35 \% .{ }^{15}$ In contrast, in other studies conducted in Pakistan, BC was the third most common lesion among all breast lesions. ${ }^{16}$ Studies conducted in Niger, Rwanda and Nigeria reported BC as the most common breast lesion, with a much higher rate of occurrence than our study, at $66 \%, 53 \%$ and $54 \%$, respectively. ${ }^{18-20}$ In Saudi Arabia, the largest proportion of breast lesions $(32.5 \%)$ was reported as $\mathrm{BC},{ }^{21}$ while studies in North America and UK recorded BC as the third most prevalent lesion in their regions. ${ }^{22-24}$ Many other studies, however, have shown fibroadenoma to be the most prevalent breast lesion and the most prevalent benign lesion. ${ }^{162526} \mathrm{BC}$ in our study mostly occurred in ages between 36 and 45 years, with the mean age of occurrence being 43.7 years. This age of occurrence of $\mathrm{BC}$ is lower than the mean age of $\mathrm{BC}$ occurrence reported by studies in Nepal and China, which reported the mean age of cancer as 54 and 47.4 years, respectively. ${ }^{27} \mathrm{~A}$ review article on $\mathrm{BC}$ from 11 Arabic countries ${ }^{28}$ reported the mean age of $\mathrm{BC}$ diagnosis as 48 years, which is also higher than the age of $\mathrm{BC}$ diagnosis in our study. The median age of BC diagnosis in USA and Germany was reported as 60 and 63 years, respectively. ${ }^{29}$ It was clearly demonstrated in our study that age at diagnosis of BC was younger than the available literature in different countries. This difference may be related to various risk factors that need to be determined by more research in Afghanistan. The significant difference of 'mean age at diagnosis' between cases diagnosed in Afghanistan and data from USA and Germany can be explained by the lower median age and life expectancy of the general population in Afghanistan as compared with that in USA and Germany. In addition, the mean age in our study was also lower than the neighbouring countries; in Iran, a study was conducted on national cancer registry data and published articles showed that the mean age in different Iranian studies was 47-50 years. ${ }^{30}$ A study in Pakistan showed the mean age of BC diagnosis to be 48.6 years. ${ }^{31}$ However, Afghanistan has no such national research data on BC epidemiology; therefore, we suggest a study of a larger scale to further evaluate the situation.

In our study there was a numerically higher proportion of left side BC (62\%) as compared with the right side. This is consistent with other studies done in $\mathrm{UK}^{32}{ }^{32} \mathrm{USA}^{33}{ }^{3} \operatorname{Iran}^{1}$ and Nigeria, which also demonstrated that $\mathrm{BC}$ was more common on the left side. ${ }^{20}$ The probable reason for breast lumps occurring on the left side is that the left breast is bulkier and have compact tissues, especially in the upper outer quadrant. ${ }^{34}$ However, a study done in Yemeni population reported right side $\mathrm{BC}$ more than the left side. ${ }^{35}$

Our study reported fibroadenoma as the second most common breast disease $(22.4 \%)$, while the most common was benign lesions $(31.8 \%)$. These findings were in line with other previous studies. ${ }^{36-39}$ The mean age at diagnosis of fibroadenoma in our study was 23.5 years, similar to other studies which also reported the mean age at fibroadenoma diagnosis to be between 20 and 30 years. ${ }^{36-39}$ In addition, cases of fibroadenoma occurred mostly before menopause, and this is consistent with other studies showing fibroadenoma to be the most common breast mass in young women. ${ }^{40}$ In general, fibroadenoma and FCC were the most prevalent benign breast disorders. ${ }^{42}$ This study also reported FCC as the third most common disease among all lesions and the second most common among benign lesions, comprising $21.8 \%$ of benign cases, with the mean age of occurrence being 36.6 years. Earlier studies reported FCC as the third most common breast lesions. ${ }^{20} 43$

Inflammatory conditions including, mastitis, breast abscess and granulomatous inflammation constituted $18.8 \%$ of cases, after benign breast disease which constituted 51\% and BC 24\%; these findings are consistent with previous studies. ${ }^{134}$ The high prevalence of inflammatory lesions of the breast in the 26-35 years age group can be explained by the fact that this is the most active phase of the reproductive age. Breasts during the reproductive age show periodic changes with menstruation, increased blood flow and dilated ducts during pregnancy and lactation, making them more susceptible to infections. ${ }^{45}$ Breast tuberculosis (TB) comprised only $0.1 \%$ of breast lesions in Western countries and up to $4 \%$ in endemic countries. Afghanistan also has higher burden of TB cases. In our study we were not able to follow up patients with the diagnosis of mastitis, in particular granulomatous mastitis, for confirmation of TB diagnosis, because they probably would have performed TB-specific tests, such as Ziehl-Neelsen stain or TB culture, in other diagnostic centres. However, unpublished data and clinical observations suggest higher breast TB cases as well.

\section{Limitations and strengths}

The limitations of our study were that the samples were confined to only one health centre and the cases were only diagnosed by FNAC with no histopathological confirmation of the lesions and subtyping. The strength is that this is the first study of such a calibre in Afghanistan. Considering the limited resources in Afghanistan, we had this opportunity to conduct our study in the only well-equipped institution in the country. Although the study is of small sample size, the results, in particular the occurrence of BC in younger ages and as the most prevalent breast lesion, can be considered in the next larger country-wide research.

\section{CONCLUSION}

$\mathrm{BC}$ is a common breast disease and is more prevalent in younger age groups in comparison with what is available 
in the literature. Considering these findings, no breast lesions should be ignored.

Contributors The hypotheses were made by RS and reviewed by JA-G. RS collected the data. Data were analysed by RS and NA. RS drafted the manuscript, with review of the literature. JA-G, RS, AMH, NA and SR were major contributors to critically revising the manuscript for important intellectual content. JA-G has given expert opinion and final revision and approval of the version to be published. All authors read and approved the final manuscript.

Funding The authors have not declared a specific grant for this research from any funding agency in the public, commercial or not-for-profit sectors.

\section{Competing interests None declared.}

Patient and public involvement Patients and/or the public were not involved in the design, or conduct, or reporting, or dissemination plans of this research.

Patient consent for publication Not required.

Ethics approval The project was approved by the Ethical Review Committee of FMIC (57-FMIC-ER-19).

Provenance and peer review Not commissioned; externally peer reviewed.

Data availability statement All data relevant to the study are included in the article or uploaded as supplementary information.

Open access This is an open access article distributed in accordance with the Creative Commons Attribution Non Commercial (CC BY-NC 4.0) license, which permits others to distribute, remix, adapt, build upon this work non-commercially, and license their derivative works on different terms, provided the original work is properly cited, appropriate credit is given, any changes made indicated, and the use is non-commercial. See: http://creativecommons.org/licenses/by-nc/4.0/.

ORCID iD

Jamshid Abdul-Ghafar http://orcid.org/0000-0002-6575-8870

\section{REFERENCES}

1 Rezaianzadeh A, Sepandi M, Akrami M, et al. Pathological profile of patients with breast diseases in Shiraz. Asian Pac J Cancer Prev 2014;15:8191-5

2 Kumar R. A clinicopathologic study of breast lumps in Bhairahwa, Nepal. Asian Pac J Cancer Prev 2010;11:855-8.

3 Likhar KS FA, Hazari RA, Gupta SG. Diagnostic role of FNAC in breast lesions. IJRRMS $\times$ 2013;3

4 Bray F, Ferlay J, Soerjomataram I, et al. Global cancer statistics 2018: GLOBOCAN estimates of incidence and mortality worldwide for 36 cancers in 185 countries. CA Cancer J Clin 2018:68:394-424.

5 The Global Cancer Observatory. Fact sheets provide a snapshot of the burden of cancer in Afghanistan. Available: http://gco.iarc.fr/ today/data/factsheets/populations/4-afghanistan-fact-sheets.pdf

6 Shrestha ACS, Karki S, Shakya G. Fine needle aspiration cytology in a palpable breast lesion. J Pathol Nepal 2011;1.

7 Ronco AL, De Stefani E, Deneo-Pellegrini H. Risk factors for premenopausal breast cancer: a case-control study in Uruguay. Asian Pac J Cancer Prev 2012;13:2879-86.

8 Zhou W, Ding Q, Pan H, et al. Risk of breast cancer and family history of other cancers in first-degree relatives in Chinese women: a case control study. BMC Cancer 2014;14:662.

9 Field AS, Raymond WA, Rickard M, et al. The international academy of cytology Yokohama system for reporting breast fine-needle aspiration biopsy cytopathology. Acta Cytol 2019;63:257-73.

10 Jayaram G, Alhady SF, Yip CH. Cytological analysis of breast lesions: a review of 780 cases. Malays J Pathol 1996;18:81-7.

11 Janaki KL, Kannan NS, Palaniappan M, et al. Profile of breast diseases in post Pubertal women assessed by clinical breast examination - a community based study in rural Pondicherry. J Clin Diagn Res 2016;10:PC07.

12 Kochhar AK, Jindal U, Singh K. Spectrum of cytological findings in fine needle aspiration cytology of breast lumps with histopathology correlation: experience in a tertiary care rural hospital in India. Asian Pac J Cancer Prev 2013;14:7257-60.

13 Ghasemzadeh S, Khayat KM, Dadmanesh M, et al. "Evaluation of prevalence and risk factors of asymptomatic masses of breast" in women visiting in khanevadeh hospital (oct 2005-2006), 2008.

14 Siddiqui MS, Kayani N, Gill MS, et al. Breast diseases: a histopathological analysis of 3279 cases at a tertiary care center in Pakistan. J Pak Med Assoc 2003;53:94-7.
15 Altaf H K, Talpur AAL, Malik AM, et al. Clinico- pathological profile of patients with breast diseases at university Hospital, Jamshoro, 2006.

16 Abdullah P, Mubarik A, Zahir N, et al. Breast lumps: what they actually represent. J Coll Physicians Surg Pak 1999;9:46-8.

17 Khurshid A, Faridi N, Arif AM, et al. Breast lesions in adolescents and young women in Pakistan-a 5 year study of significance of early recognition. Asian Pac J Cancer Prev 2013;14:3465-7.

18 Pace LE, Dusengimana J-MV, Hategekimana V, et al. Benign and malignant breast disease at Rwanda's first public cancer referral center. Oncologist 2016;21:571-5.

19 Zouladeny H, Dille I, Wehbi NK, et al. Epidemiologic and clinical profiles of breast diseases in niger. Int J Cancer Oncol 2015;2

20 Anyanwu S, Chianakwana G, Egwuonwu OA, et al. Breast lumps in NAUTH, Nnewi: a 5 year review. Nigerian J Surg 2009;15.

21 Awatif A, Jamal A. FRCPC: pattern of breast diseases in a teaching hospital in Jeddah. Saudi Arabia Saudi Med J 2000;22.

22 Sterns EE. Age-related breast diagnosis. Can J Surg 1992;35:41-5

23 Kerlikowske K, Smith-Bindman R, Ljung B-M, et al. Evaluation of abnormal mammography results and palpable breast abnormalities. Ann Intern Med 2003;139:274-84.

24 Ellis $\mathrm{H}$, Cox PJ. Breast problems in 1,000 consecutive referrals to surgical out-patients. Postgrad Med J 1984;60:653-6.

25 Shirley SE, Mitchell DIG, Soares DP, et al. Clinicopathologic features of breast disease in Jamaica: findings of the Jamaican breast disease study, 2000-2002. West Indian Med J 2008;57:90-4.

26 Singh A, Haritwal A, Murali B. Pattern of breast lumps and diagnostic accuracy of fine needle aspiration cytology; a hospital based study from Pondicherry, India. Internet J Pathol 2011;11:1-6.

27 Song Q-K, Li J, Huang R, et al. Age of diagnosis of breast cancer in China: almost 10 years earlier than in the United States and the European Union. Asian Pac J Cancer Prev 2014;15:10021-5.

28 Najjar H, Easson A. Age at diagnosis of breast cancer in Arab nations. Int J Surg 2010;8:448-52.

29 Gondos A, Arndt V, Holleczek B, et al. Cancer survival in Germany and the United States at the beginning of the 21st century: an up-todate comparison by period analysis. Int J Cancer 2007;121:395-400.

30 Nafissi N, Khayamzadeh M, Zeinali Z, et al. Epidemiology and histopathology of breast cancer in Iran versus other Middle Eastern countries. Mid East J Cancer 2018;9:243-51.

31 Badar F, Mahmood S, Yusuf MA, et al. Epidemiology of cancers in Lahore, Pakistan, 2010-2012: a cross-sectional study. BMJ Open 2016;6:e011828.

32 Lee AHS. Why is carcinoma of the breast more frequent in the upper outer quadrant? A case series based on needle core biopsy diagnoses. Breast 2005;14:151-2.

33 Perkins $\mathrm{Cl}$, Hotes J, Kohler BA, et al. Association between breast cancer laterality and tumor location, United States, 1994-1998. Cancer Causes Control 2004;15:637-45.

34 Sandhu DS, Sandhu S, Karwasra RK, et al. Profile of breast cancer patients at a tertiary care hospital in North India. Indian J Cancer 2010;47:16-22

35 Alsanabani JA, Gilan W, Saadi AA. Incidence data for breast cancer among Yemeni female patients with palpable breast lumps. Asian Pac J Cancer Prev 2015;16:191-4.

36 Amr SS, Sa'di AR, llahi F, et al. The spectrum of breast diseases in Saudi Arab females: a 26 year pathological survey at Dhahran health center. Ann Saudi Med 1995;15:125-32.

37 Abdulkader MA. Profle of benign breast diseases in Western Saudi Arabia. An 8-year histopathological review of 603 cases. Saudi Med J 2014;35.

38 Awatif A, Jamal M. FRCPC: pattern of breast diseases in a teaching hospital in Jeddah, Saudi Arabia. Saudi Med J 2001;22.

39 Njeze GE. Breast lumps: a 21-year single-center clinical and histological analysis. Niger J Surg 2014;20:38-41.

40 Bock K, Duda VF, Hadji P, et al. Pathologic breast conditions in childhood and adolescence: evaluation by sonographic diagnosis. $J$ Ultrasound Med 2005;24:1347-54.

41 Al-Rikabi A, Husain S. Increasing prevalence of breast cancer among Saudi patients attending a tertiary referral Hospital: a retrospective epidemiologic study. Croat Med J 2012;53:239-43.

42 Sirous M. EBRAHIMI A: the epidemiology of breast masses among women in Esfahan, 2008.

43 Jeje EA, Mofikoya BO, Oku YE. Pattern of breast masses in Lagos: a private health facility review of 189 consecutive patients. Nig Q J Hosp Med 2010;20:38-41.

44 Khokher S, Qureshi MU, Riaz M, et al. Clinicopathologic profile of breast cancer patients in Pakistan: ten years data of a local cancer Hospital. Asian Pac J Cancer Prev 2012;13:693-8.

45 Shinde SR, Chandawarkar RY, Deshmukh SP. Tuberculosis of the breast masquerading as carcinoma: a study of 100 patients. World $J$ Surg 1995;19:379-81. 